\title{
The Role of Proximal Sensors to Improve Land Management, Meet Environmental Targets and Increase Nutrient Use Efficiency on Farms
}

ISSN: 2637-7659

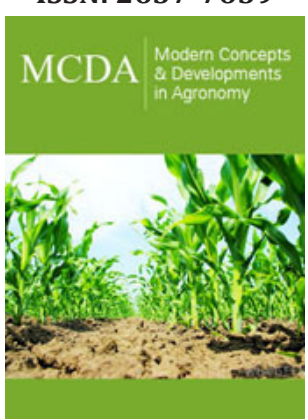

*Corresponding author: Higgins S, Agri Food and Biosciences Institute, Belfast BT9 5PX, UK

Submission: 漹 September 20, 2021

Published: 侮October 08, 2021

Volume 9 - Issue 4

How to cite this article: Higgins S, McConnell D. The Role of Proximal Sensors to Improve Land Management, Meet Environmental Targets and Increase Nutrient Use Efficiency on Farms. Mod Concep Dev Agrono. 9(4). MCDA. 000718. 2021 DOI: 10.31031/MCDA.2021.09.000718

Copyright@ Higgins S. This article is distributed under the terms of the Creative Commons Attribution 4.0 International License, which permits unrestricted use and redistribution provided that the original author and source are credited.
Higgins S* and McConnell D

Agri Food and Biosciences Institute, Belfast BT9 5PX, UK

\begin{abstract}
Increasing nutrient use efficiency on farms; improving land management; changing land use to capture more carbon, along with boosting renewable energy and the wider bio economy are practices that have been identified as key mechanisms by which the ambitious goal of achieving carbon net zero by 2050 can be achieved [1,2]. In order to increase nutrient use efficiency on farms, it requires knowledge and data collection to manage inputs, outputs, emissions and productivity. Soil and crop sensors can play an important role in improving the precision of agricultural practices while minimising harmful emissions to the environment. Rapid advances in technology mean that today there are many soil and crop sensors which provide a fast, powerful, non-destructive means of measuring a large number of chemical and physical properties. However, disentangling the data provided by soil and crop sensors can often be a challenge, particularly as some sensors and proximal sensor systems can be good proxies for more than one soil property. While it is possible to create very accurate and detailed soil maps using proximal sensors, there is nearly always a requirement to calibrate with local samples, as multiple factors can affect sensor measurements [3]. Good processing and calibration are key, and the best results will be achieved when there is a wide variation of in-field properties [4]. This mini review identifies two important case examples where proximal sensors can improve land management and farm nutrient use efficiency, which are both important concepts towards carbon net zero.
\end{abstract}

\section{Introduction}

Electromagnetic induction (EMI) is a widely applied proximal sensing technology which measures the apparent electrical conductivity ( $E C_{a}$ ) of soil, as a proxy for a number of physicochemical properties such as soil texture, clay content, salinity and soil water content $[5,6]$. The use of ancillary data such as $\mathrm{EC}_{2}$, is quick, non-invasive and inexpensive, and provides an alternative to costly, labour intensive manual soil sampling, which is a key factor in determining the likelihood of farmers adopting site-specific management [7-9]. Along with soil physicochemical properties, factors such as the aggregation of soil particles by cementing agents such as clay and organic matter, the concentration of electrolytes in the soil water and the conductivity of the soil mineral phase are all important $[10,11]$.

\section{Case example 1: EMI scanning to map soil $\mathrm{EC}_{\mathrm{a}}$ across a $50 \mathrm{ha}$ grassland farm site}

McCormick et al. [12] carried out EMI scanning as a surrogate measure or indicator of specific soil properties that might be responsible for spatial variation in grass silage yield. Manual soil sampling at georeferenced locations across a number of fields provided calibration and ground truthing. Across a $50 \mathrm{ha}$ farm site, soil EC $\mathrm{a}_{\mathrm{a}}$ varied by $14.3 \mathrm{mSm}^{-1}$ (Figure 1). From multivariate regression analysis, $52 \%$ of the variation in soil $\mathrm{EC}_{\mathrm{a}}$ could be explained by soil moisture, soil stone content, and the magnesium (Mg) content of the soil (Equation 1) 


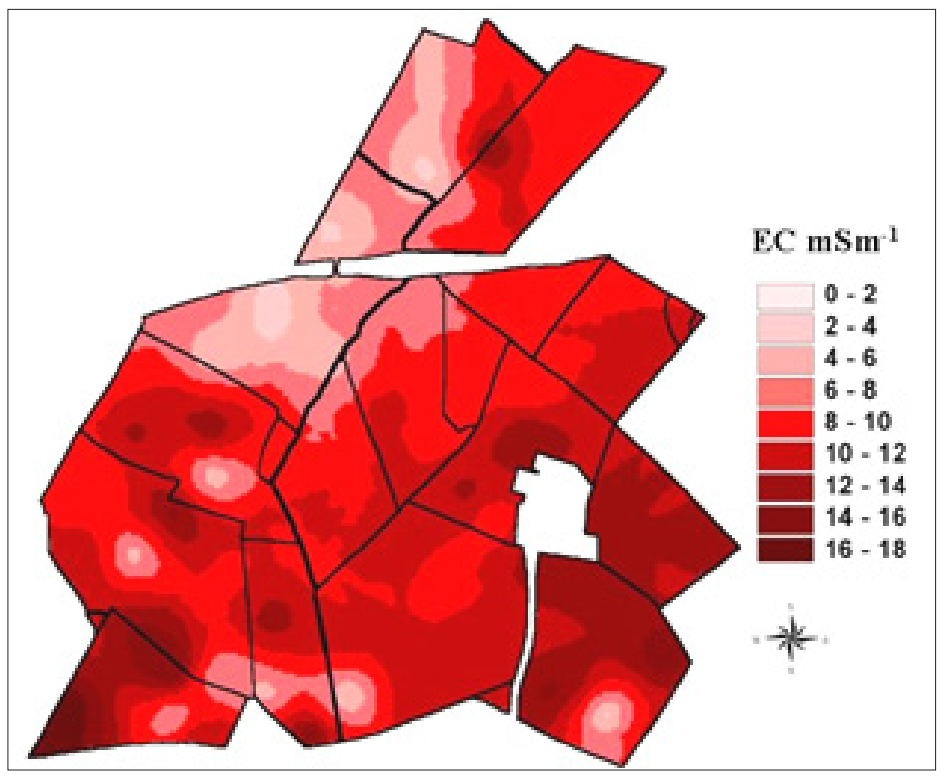

Figure 1: Map of soil ECa across a 50ha grassland farm site, produced by inverse-distance weighted interpolation. 6.98

Soil $\mathrm{EC}_{\mathrm{a}}=38.94$ (\% moisture $)-0.14$ (\% stones $)+0.03($ Extr Mg)-

\section{$\left(\mathrm{R}^{2}=0.52\right)$ Equation 1}

Soil moisture content alone explained almost $40 \%$ of the variation in soil $\mathrm{EC}_{\mathrm{a}}$ on this farm. Soil moisture results in greater conductivity in the soil by providing a medium for the electromagnetic field to travel through the soil. Other authors such as Hartsock et al. [13] and Sheets et al. [14] found similar correlations between soil $\mathrm{EC}_{\mathrm{a}}$ with soil moisture. Kravchenko et al. [15] used soil EC $\mathrm{a}_{\mathrm{a}}$ to create soil drainage maps. The ability of EMI-scanning to provide a reliable indication of soil moisture content is important because it means that areas in fields with potential drainage or drought problems or areas where there is a tendency for the soil to suffer from waterlogging or where there could be an increased tendency for denitrification due to high soil water contents, might be objectively and rapidly identified. As soil moisture is a critical driver of nitrous oxide $\left(\mathrm{N}_{2} \mathrm{O}\right)$ emissions [16], field $\mathrm{EC}_{\mathrm{a}}$ maps created by EMI scanning could help identify areas where care with nitrogen (N) management would be important, to help reduce $\mathrm{N}_{2} \mathrm{O}$ emissions following $\mathrm{N}$ fertiliser and manure applications. The relationship between $\mathrm{EC}_{\mathrm{a}}$ and soil $\mathrm{Mg}$ content at the site could be related to historical high applications of organic manures to these fields.

Case example 2: EMI scanning, ground penetrating radar and visible near infrared to assess peatland carbon (C) storage

Peatlands store large amounts of soil organic C, making them both a valuable sink, but also a source of $\mathrm{CO}_{2}$ [17]. Obtaining reliable information about the spatial heterogeneity of peat soils and the amount of $\mathrm{C}$ stored at various scales has been receiving considerable interest of late. Manual soil coring to assess $\mathrm{C}$ is incredibly laborious [17]. Non-invasive mapping of easily recordable proxies that correlate with soil C, such as colour, dielectric permittivity and bulk $\mathrm{EC}_{\mathrm{a}}$, offer promising alternatives. Visible near infrared technique (Vis-NIR) is a proven method for identifying soil colour, based on light absorbance of soil components in the Vis-NIR range $[17,18]$. With the ability to measure at more than one depth within the soil profile, ground penetrating radar and EMI scanning, along with Vis-NIR are promising methods for providing detailed information about our peatland soils without the need for laborious manual sampling. Altdorff et al. [17] concluded that it is possible to directly estimate soil organic carbon (SOC) stocks at the field scale, allowing an assessment of the size of the entire vulnerable $C$ pool of a disturbed peatland area [19].

\section{Conclusion}

Mapping of proxy variables, such as $\mathrm{EC}_{\mathrm{a}}$ by soil EMI scanning, allows for indirect, cost effective and non-invasive mapping of soil properties at various scales. When assessing the data provided by proximal sensors, care should be taken to avoid making assumptions as to the causes of the variability, due to the number of interacting factors contributing to spatial and temporal variability of soil and crop variables. An element of calibration and field sampling is still required. However, the real benefit is in the speed and low cost through which large amounts of data can be obtained. Mapping of this data can provide the basis for a more targeted sampling regime of specific soil properties of interest, be that nutrients, C, moisture, soil texture or salinity.

\section{References}

1. NFU (2019) Achieving Net Zero. Farming's 2040 goal. National Farmers Union publication.

2. EIP-AGRI (2021) EIP-AGRI Workshop. Towards carbon neutral agriculture. Workshop Report 2021. European Commission. 
3. Bjørn Møller A, Koganti T, Beucher A, Iversen BV, Greve MH (2021) Downscaling digital soil maps using electromagnetic induction and aerial imagery. Geoderma 385: 114852.

4. Kempenaar C, Tigchelhoff F, Booij JA, Nysten S, Kocks CG (2021) Validation of precision agriculture soil mapping services under practical conditions. John V Stafford (Ed.), Precision agriculture, (CWageningen Academic Publishers.

5. Altdorff D, Sadatcharam K, Unc A, Krishnapillai M, Galagedara L (2020) Comparison of multi-frequency and multi-coil electromagnetic induction (EMI) for mapping properties in shallow podsolic soils. Sensors 20(8): 2330.

6. Corwin DL, Lesch SM (2005) Characterizing soil spatial variability with apparent soil electrical conductivity: Part II. Case study. Computers \& Electronics in Agriculture 46(1-3): 135-152.

7. Doolittle JA, Sudduth KA, Kitchen NR, Indorante SJ (1994) Estimating depths to claypans using electromagnetic induction methods. Journal of Soil and Water Conservation 49(6): 572-575.

8. Kitchen NR, Sudduth KA, Drummond ST (1996) Mapping of sand deposition from 1993 Midwest floods with electromagnetic induction measurements. Journal of Soil and Water Conservation 51: 336-340.

9. Kitchen NR, Sudduth KA, Drummond ST (1999) Soil electrical conductivity as a crop productivity measure for claypan soils. Journal of Production Agriculture 12(4): 607-617.

10. Rhoades JA, Manteghi NA, Shouse PJ, Alves WJ (1989) Soil electrical conductivity and soil salinity: new formulations and calibrations. Soil Science Society of America Journal 53(2): 433-439.

11. McNeil JD (1980) Electrical conductivity of soil and rocks. Technical Note TN-5 Geonics Ltd. Mississauga, Ontario, Canada, p: 20.
12. McCormick S, Bailey JS, Jordan C, Higgins AJ (2003) A potential role for soil electrical conductivity mapping in the site-specific management of grassland. John V Stafford (Ed.), Precision agriculture, pp: 393-397.

13. Hartsock NJ, Mueller TG, Thomas GW, Barntusel RI, Wells KL, et al. (2000) Soil electrical conductivity variability. Proceedings of the fifth International Conference on Precision Agriculture, Bloomington, Minnesota, USA.

14. Sheets KR, Hendrickx JMH (1995) Noninvasive soil water content measurement using electromagnetic induction. Water Research 31: 2401-2409.

15. Kravachenko AN, Bollero GA, Omonode RA, Bullock DG (2002) Quantitative mapping of soil drainage classes using topographical data and soil electrical conductivity. Soil Science Society of America Journal 66: 235-243.

16. Krol DJ, Carolan R, Minet E, McGeough KL, Watson CJ, et al. (2016) Improving and disaggregating $\mathrm{N} 20$ emission factors for ruminant excreta on temperate pasture soils. Sci Total Environ 568: 327-338.

17. Altdorff D, Bechtold M, van der Kruk J, Vereecken H, Huisman JA (2016) Mapping peat layer properties with multi-coil offset electromagnetic induction and laser scanning elevation data. Geoderma 261: 178-189.

18. Higgins S, Schellberg J, Bailey JS (2019) Improving productivity and increasing the efficiency of soil nutrient management on grassland farms in the UK and Ireland using precision agriculture technology. European Journal of Agronomy 106: 67-74.

19. Viscarra Rossel RA, Walvoort DJJ, McBratney AB, Janikc LJ, Skjemstad JO (2006) Visible, near infrared, mid infrared or combined diffuse reflectance spectroscopy for simultaneous assessment of various soil properties. Geoderma 131(1-2): 59-75. 